\title{
Increased Binding of Synovial T Lymphocytes from Rheumatoid Arthritis to Endothelial-Leukocyte Adhesion Molecule-1 (ELAM-1) and Vascular Cell Adhesion Molecule-1 (VCAM-1)
}

\author{
Antonio A. Postigo, * Rosario Garcia-Vicuña, ${ }^{\ddagger}$ Federico Diaz-Gonzalez, ${ }^{\star}$ Alicia G. Arroyo, ${ }^{*}$ Manuel O. De Landázuri, \\ Gloria Chi-Rosso, Roy R. Lobb, Armando Laffon, ${ }^{\star}$ and Francisco Sánchez-Madrid* \\ *Servicios de Inmunología and ${ }^{\ddagger}$ Reumatología, Hospital de la Princesa, Universidad Autónoma de Madrid, Madrid, Spain; \\ and ${ }^{\S}$ Biogen Inc., Cambridge, Massachusetts 02142
}

\begin{abstract}
The infiltration of the synovial membrane (SM) by mononuclear cells, mostly $T$ cells, is a typical histopathological feature associated with rheumatoid arthritis (RA). The entry of T lymphocytes into the SM is believed to be mediated by a number of molecules in the endothelium that are induced in response to a series of inflammatory mediators. In this study, we have investigated the adhesion of synovial $T$ cells from $R A$ patients to two endothelial ligands: endothelial-leukocyte adhesion molecule-1 (ELAM-1), the only selectin known to function as a vascular addressin for $T$ cells, and vascular cell adhesion molecule-1 (VCAM-1), the cellular ligand of VLA-4. Our results clearly demonstrate that synovial $T$ cells isolated from both $\mathrm{SM}$ and synovial fluid (SF), bearing an activated and memory phenotype, displayed an enhanced capacity to interact with these two endothelial molecules as compared with $T$ cells from peripheral blood (PB) either of the same RA patients or healthy donors. A further enhancement of VLA-4-mediated $T$ cell binding to VCAM-1 and fibronectin could be observed when already in vivo-activated synovial $T$ cells were stimulated in vitro with phorbol esters, suggesting the existence of several cellular affinity levels for both very late activation-4 (VLA-4) ligands. Moreover, both PB and synovial $T$ cells from RA patients exhibited strong proliferative responses when they were cultured with either fibronectin or VCAM-1 in combination with submitogenic doses of anti-CD3 $\mathrm{mAb}$. This increased endothelial binding ability of synovial $T$ lymphocytes together with their proliferation in response to the interaction with VCAM-1 and fibronectin may represent important mechanisms in the regulation of $T$ cell penetration and persistence in the chronically inflamed SM of RA. (J. Clin. Invest. 1992. 89:1445-1452.) Key words: rheumatoid arthritis $\bullet T$ cell adhesion • endothelium - selectins • integrins
\end{abstract}

\section{Introduction}

RA constitutes one of the paradigms of chronic inflammatory processes in humans. $\mathrm{T}$ cells emigrating from peripheral blood

Address correspondence and reprint requests to Dr. F. Sanchez-Madrid, Servicio de Immunologia, Hospital de la Princesa, C/Diego de Leon 62, 28006 Madrid, Spain. 1992.

Received for publication 26 July 1991 and in revised form 2 January

J. Clin. Invest.

(c) The American Society for Clinical Investigation, Inc.

$0021-9738 / 92 / 05 / 1445 / 08 \quad \$ 2.00$

Volume 89, May 1992, 1445-1452
(PB) ${ }^{1}$ and infiltrating the RA synovial membrane (SM) are believed to play an important role in the pathogenesis of the disease (1-4). The entry of PB T lymphocytes to the SM requires, as a first step, the binding of $\mathrm{T}$ cells to the endothelium (reviewed in refs. 2 and 3). A wide array of adhesion molecules has been described to be involved in this interaction (5-8). Recent reports indicate that the initial leukocyte interaction with endothelium is mediated by CD62 (PADGEM/GMP140) and endothelial-leukocyte adhesion molecule-1 (ELAM-1) molecules that belong to a newly described group of structurally related cell adhesion receptors, termed selectins (9-14), which also include the MEL-14/LAM-1 homing receptor (15). In myeloid cells, certain carbohydrate determinants, Lewis $\times$ and sialylated Lewis $\times$ epitopes, have been described as ligands for CD62 and ELAM-1 (16-20). A T cell subset has been demonstrated to bind to the endothelial ELAM-1 molecule; however, the T cell counter receptor for this selectin remains unidentified (21-23).

Once the leukocyte selectin-mediated binding to endothelial cells (EC) has taken place, the leukocyte integrins and their counter receptors in EC participate in the subsequent shear-resistant attachment to endothelium, and in the penetration into the inflammed tissue (11-14). Integrins, comprising a group of $\alpha \beta$ heterodimers involved in both cell-cell contacts and cell-extracellular matrix $(\mathrm{ECM})$ interactions $(7,8)$, have also been implicated in lymphocyte binding to endothelium. While lymphocyte function associated antigen-1 (LFA-1) interacts with ICAM-1 and ICAM-2 (24-26), very late antigen-4 (VLA-4) integrin binds to other endothelial ligand known as vascular cell adhesion molecule-1 (VCAM-1)/inducible cell adhesion molecule 110 (INCAM-110) $(27,28)$. VLA-4 is the only integrin that, in addition to its involvement in leukocyte-endothelial adhesion, has also been implicated in the attachment to the ECM component fibronectin (FN) $(29,30)$.

The pathogenesis of RA lesions remains controversial. Some reports show the increment of an activated circulating $T$ cell population in RA (31) which should, therefore, be able to migrate and bind to EC in SM. Other authors emphasize the role of local factors within the SM itself, especially infiltrating $T$ lymphocytes (reviewed in references 2 and 4). In any case, an upregulated expression of some adhesion molecules (VLA-1 and VLA-4), as well as the expression of a memory

1. Abbreviations used in this paper: EC, endothelial cells; ECM, extracellular matrix; ELAM-1, endothelial-leukocyte adhesion molecule-1; FN, fibronectin; FN38, 38-kD proteolytic FN; MFI, mean fluorescence intensity; MNC, mononuclear cells; PB, peripheral blood; PMA, phorbol 12 myristate 13 acetate; rsELAM-1, recombinant soluble ELAM-1; rsVCAM-1, recombinant soluble VCAM-1; SF, synovial fluid; SM, synovial membrane, VLA, very late antigens. 
(CD45RO+) and activated (HLA-DR, CD69/AIM) phenotype by synovial $\mathrm{T}$ cells, have been recently documented (32-37).

In this study, we have investigated the binding of T lymphocytes isolated from the three compartments (peripheral blood, synovial membrane, and synovial fluid [SF]) of RA patients to two adhesion molecules specifically expressed by activated endothelial cells: ELAM-1 and VCAM-1. Our results show an upregulated $\mathrm{T}$ cell adhesiveness to both EC ligands, as well as an increased attachment to FN. The significance of these phenomena are discussed in the context of the RA pathogenesis.

\section{Methods}

Patients. 13 patients diagnosed as having RA according to American College of Rheumatology criteria (38) were studied. SF and PB were collected from all of them. Synovial tissue was obtained during synovectomy in two of these RA patients undergoing knee surgery. Their mean age was $55.1 \mathrm{yr}$ (ranging from 30 to $60 \mathrm{yr}$ ), and the duration of disease ranged from 2 mo to $40 \mathrm{yr}$, with a mean of $12 \mathrm{yr}$ of evolution. Four patients were taking nonsteroidal antinflammatory drugs, four were on prednisone $(<20 \mathrm{mg} / \mathrm{d})$, two patients were treated with methotrexate, three were treated with gold salts, one with antimalarial compounds, and one with D-penicillamine.

Monoclonal antibodies. CD3 SPV-T3b mAb was kindly provided by Dr. De Vries (UNICET Labs, Dardilly, France) (39). HP2/1 is directed against $\alpha 4$ chain of VLA-4 (40). TS $2 / 16 \mathrm{mAb}$ recognizes the $\beta 1$ common chain of VLA family, and was previously characterized (41) Anti-VCAM-1 4B9 mAb (42) was the generous gift of Dr. Harlan (University of Washington, Seattle, WA). BB $11 \mathrm{mAb}$ recognizes ELAM-1, as previously described (43). TP1/55 and TP1/8 mAb, recognizing AIM/CD69, and D3/9 mAb, directed against CD45, were obtained in our laboratory $(44,45)$. Anti-CD45RO UCHL1 mAb was kindly supplied by Dr. Beverley (Imperial Cancer Res. Fund, London, UK) (46). CSLEX $1 \mathrm{mAb}$ that recognizes sialylated Lewis $\mathrm{x}$ antigen was generously provided by Dr. Hardy (University of California, Los Angeles, CA.) (47).

Cell isolation and culturing. Peripheral blood and SF samples were collected at the same time on heparinized tubes. T cells ( $>90 \% \mathrm{CD} 3+$ and $<2 \% \mathrm{CD} 1 \mathrm{lb}+$ and $\mathrm{CD} 19+$ ) were purified from mononuclear cells (MNC) obtained after Lymphoprep (Nycomed Pharma AS, Oslo, Norway) gradient centrifugation and removal of adherent cells on plastics flasks (Costar Corp., Cambridge, MA). Purification was achieved by passage through nylon wool columns (DuPont/NEN, Boston, MA). Peripheral blood $\mathrm{T}$ cells from five voluntary healthy donors were obtained as described for RA patients' $T$ cells.

Synovial membranes (SM) obtained at the time of surgery from RA patients were treated for $2 \mathrm{~h}$ at $37^{\circ} \mathrm{C}$ with $2 \mathrm{mg} / \mathrm{ml}$ of type $\mathrm{P}$ collagenase (Boehringer Manheim Diagnostics, GmbH, Germany) in serum-free RPMI 1640 culture medium (Flow Laboratories, Inc., Irvine, Scotland). Cells were maintained overnight at $37^{\circ} \mathrm{C}$ in RPMI 1640 supplemented with $10 \%$ FCS, $2 \mathrm{mM}$ L-glutamine, $50 \mathrm{U} / \mathrm{ml}$ penicillin, and 50 $\mu \mathrm{g} / \mathrm{ml}$ streptomicin (all from Flow Laboratories Inc.) (complete medium). After overnight incubation, nonadherent cells were subjected to a Lymphoprep gradient centrifugation, and MNC so obtained passed through nylon-wool columns. This T cell-enriched population was $>90 \% \mathrm{CD} 3+$ and $<2 \%$ of CD19+, CD1 lb, or CD14+.

Reagents. Phorbol 12 myristate 13 acetate (PMA) and $\mathrm{F}\left(\mathrm{ab}^{\prime}\right) 2$ fragments of sheep anti-mouse IgG antiserum were purchased from Sigma Chemical Co. (St. Louis, MO).

Flow cytometry analysis. T cells were incubated with hybridoma culture supernatants for 30 min at $4^{\circ} \mathrm{C}$. After two washes with cold PBS, the cells were stained with a goat anti-mouse $F\left(a b^{\prime}\right) 2$ fragmentFITC (Dakopatts, Copenhagen, Denmark), followed by another two washes with cold PBS. Single color fluorescence was analyzed by flow cytometry, using a EPICS-C (Coulter, Corp., Hialeah, FL). The final percentage of positive cells was obtained by subtracting the values of negative control $\times 63$ from those obtained with every specific marker.
Cell attachment assays. Recombinant soluble VCAM-1 (rsVCAM1) and ELAM-1 (rsELAM-1) were purified by immunoaffinity chromatography from conditioned medium of Chinese hamster ovary (CHO) cells stably transfected with a truncated cDNA for VCAM-1 and ELAM-1, respectively $(23,48)$. A 38-kD proteolytic fibronectin (FN38) fragment was kindly supplied by Dr. A. García-Pardo (Centro de Investigaciones Biológicas, CSIC, Madrid), and obtained as described (29). Type I collagen was purchased from Sigma Chemical Co.

Adhesion assays were performed as previously described (37). Briefly, 96-well microtiter EIA II Linbro plates (Flow Laboratory Inc.) were coated overnight at $4^{\circ} \mathrm{C}$ with $50 \mu \mathrm{l}$ of different proteins $(40 \mu \mathrm{g} / \mathrm{ml}$ of FN38 or collagen, and $10 \mu \mathrm{g} / \mathrm{ml}$ of rsVCAM-1 or rsELAM-1) dissolved in $\mathrm{CO} 3 \mathrm{HNa} 0.1 \mathrm{M}$. Unbound sites were saturated with RPMI $1640-1 \% \mathrm{HSA}$ for $2 \mathrm{~h}$ at $37^{\circ} \mathrm{C}$. Thereafter, plates were gently washed with RPMI 1640 and $1.5 \times 10^{5}$ cells in $100 \mu$ l were added to wells and incubated for $30 \mathrm{~min}$ at $37^{\circ} \mathrm{C}$. Then, plates were washed three times and examined in an inverted microscope by at least two independent observers. Each condition was performed in duplicate. Within each well, cells from at least three different fields were counted. The number of cells counted in a nonwashed well was considered as maximum binding. In inhibition assays, cells were incubated for $30 \mathrm{~min}$ at $4^{\circ} \mathrm{C}$ with $25 \%$ final volume of hybridoma culture supernatants of anti- $\alpha 4$ $\mathrm{HP} 2 / 1$ or anti-CD45 D3/9 mAb, or with purified anti-VCAM-1 $4 \mathrm{~B} 9$ or anti-ELAM-1 BB11 mAb at $10 \mu \mathrm{g} / \mathrm{ml}$.

Proliferation assays. Flat-bottomed 96-well culture plates (Costar Corp.) were coated with $50 \mu$ l of anti-CD3 SPV T3b mAb at $2 \mu \mathrm{g} / \mathrm{ml}$ $\left(100 \mathrm{ng} /\right.$ well) in $\mathrm{PBS} \mathrm{pH}$ 8.0. Upon $4 \mathrm{~h}$ incubation at $37^{\circ} \mathrm{C}$, plates were gently washed with RPMI 1640, and $50 \mu$ l of either FN38 fragment or rsVCAM-1 at $10 \mu \mathrm{g} / \mathrm{ml}(500 \mathrm{ng} /$ well) was added and reincubated for another $4 \mathrm{~h}$ at $37^{\circ} \mathrm{C}$. Plates were gently washed again with RPMI 1640. Purified PB and SF T lymphocytes at $0.75 \times 10^{6} / \mathrm{ml}$ were added in 100 $\mu$ l of RPMI $1640-10 \%$ FCS to wells completing, to reach $200 \mu$ l, with complete medium or other stimuli (PMA at $2 \mathrm{ng} / \mathrm{ml}$ or anti-CD69 $\mathrm{TP} 1 / 8 \mathrm{mAb}$ at $2 \mu \mathrm{g} / \mathrm{ml}$ ). Plates were incubated for $72 \mathrm{~h}$ in a $37^{\circ} \mathrm{C}$ and $5 \% \mathrm{CO}_{2}$ atmosphere. Cell proliferation was estimated by $\left[{ }^{3} \mathrm{H}\right] \mathrm{TdR}(\mathrm{Du}-$ Pont) incorporation during the last $18 \mathrm{~h}$ of culture. Cells were harvested in a cell harvester (Skatron, Lier, Norway), and the radioactivity measured in a liquid scintillation $\beta$ counter (Kontron Analytical, Zurich, Switzerland).

Statistical analysis. Statistical analysis was performed using Student's $t$ test in the SIGMA-TM database program.

\section{Results}

Enhanced binding to the ELAM-1 selectin by a synovial T cell subset. It has recently been described that a subset of normal memory CD45RO+ $T$ cells, as well as some $T$ cells isolated from chronic inflammatory lesions of skin, interact with ELAM-1 in an activation-independent manner (21-23, 49). The expression of ELAM-1 on EC from a variety of inflammatory processes, including RA, has been documented $(49,50)$. Therefore, we investigated the interaction of synovial $\mathrm{T}$ cells, most of them expressing a memory CD45RO+ phenotype (Table I), with rsELAM-1. Synovial T cells derived from both SM and SF displayed a significantly higher binding (approximately twofold) to rsELAM-1, as compared with either patients' and healthy donors' PB T cells (Fig. 1). The typical pattern of enhanced attachment to rsELAM- 1 by PB and SF T cells from one RA patient is illustrated in Fig. 2, $A$ and $B$.

The specificity of this binding was confirmed by its inhibition by anti-ELAM-1 BB1 $1 \mathrm{mAb}$, and the lack of effect of anti-CD45 D3/9 mAb (Fig. 1 and data not shown). No significant binding to collagen or albumin was observed (see below and data not shown). No expression of the sialylated Lewis $X$ carbohydrate determinant was demonstrable by flow cytome- 
Table I. Expression of VLA-4, CD69/AIM and CD45RO Antigens by T Cells from PB, SM, and SF of RA Patients, and from $P B$ of Healthy Donors

\begin{tabular}{|c|c|c|c|c|c|c|c|c|c|c|}
\hline \multirow[b]{2}{*}{$\mathrm{CD}$} & \multirow{2}{*}{$\begin{array}{l}\text { Antigen } \\
\text { specificity }\end{array}$} & \multirow[b]{2}{*}{$\mathrm{mAb}$} & \multirow{2}{*}{\multicolumn{2}{|c|}{$\frac{\text { Healthy donors }}{\text { PB }}$}} & \multirow[b]{2}{*}{ PB } & \multicolumn{3}{|c|}{ RA patients } & \multirow[b]{2}{*}{ SM } & \multirow[b]{2}{*}{$\mathrm{SF}$} \\
\hline & & & & & & SM & $\mathrm{SF}$ & PB & & \\
\hline & & & $\%$ & $M F I$ & & $\%^{*}$ & & & $M F I$ & \\
\hline CD49d & $\alpha 4$ (VLA- $\alpha 4)$ & HP2/1 & 53 & 46 & 43 & 71 & 73 & 44 & 71 & 60 \\
\hline CD29 & $\beta 1$ (VLA- $\beta$ ) & TS2/16 & 65 & 56 & 56 & 96 & 83 & 63 & 100 & 85 \\
\hline CD69 & AIM & TP1/55 & 2 & 23 & 8 & 68 & 50 & 28 & 73 & 58 \\
\hline CD45RO & LCA & UCHL-1 & 41 & 39 & 37 & 65 & 74 & 40 & 95 & 90 \\
\hline- & - & $\times 63$ & & 16 & & & & 16 & 20 & 16 \\
\hline
\end{tabular}

* The expression of both $\alpha 4$ and $\beta 1$ chains of VLA-4 integrin, the CD69/AIM activation antigen, and the CD45RO memory marker, was analyzed by immunofluorescence flow cytometry in T cells from PB of healthy donors, and T cells isolated from different compartments of RA patients. Values represent the percentage of positive cells and were calculated as described in Methods. Mean fluorescence intensity (MFI) values are expressed in a logarithmic scale.

try analysis on either PB or SF T cells (data not shown), indicating that these glycosylated epitopes, present on myeloid cells $(18,19)$, are not incriminated in the observed $\mathrm{T}$ cell interactions with ELAM-1.

Most synovial $T$ cells from rheumatoid arthritis patients bind to VCAM-1. The expression of VCAM-1 has been detected on EC, synovial macrophages, and in the lining layer macrophages of RA synovial tissue (50-51). Very recently, in vitro activation has been described to induce a strong enhancement in T cell binding to VCAM-1 (52). Moreover, a higher expression of both VLA-4 chains, as well as some activation antigens (CD69/AIM, HLA-DR), could be noticed in synovial $T$ cells isolated from both SM and SF, as compared with PB (Table I). Therefore, we explored the binding of in vivo-activated synovial $T$ cells from RA patients, as well as their PB T cells, to rsVCAM-1. The majority of synovial $\mathrm{T}$ cells from both SF and SM were able to bind to rsVCAM-1, in contrast to the low binding typical for PB T lymphocytes from those patients, as well as healthy donors (Fig. 3). The differential capacity of SF and PB RA T cells in adhesion to rsVCAM-1 could be evidenced in Fig. 2, $C$ and $D$.

This upregulated T cell attachment to rsVCAM-1 was specifically mediated by VLA- 4 integrin, since it was virtually

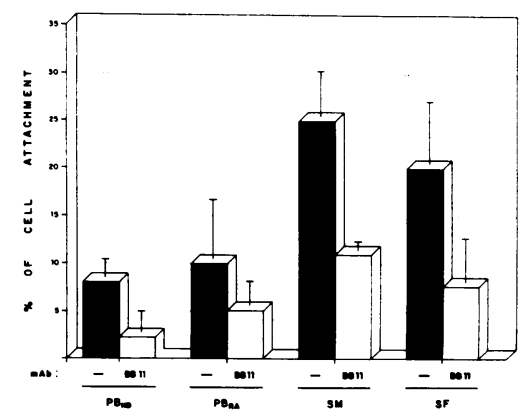

Figure 1. Binding to rsELAM-1 by $T$ cells from PB of healthy donors, and from different compartments of RA patients. $\left(P B_{H D}\right) \mathrm{T}$ cells from $\mathrm{PB}$ of healthy donors; $\left(P B_{R A}\right) T$ cells from PB of RA patients; $(S M)$ T cells isolated from SM of RA patients; $(S F)$ T cells isolated from the SF of RA patients. Adhesion assays were performed as described in Methods, either in the absence or presence of anti-ELAM-1 BB 11 mAb. All the inhibitions with the $\mathrm{BB} 11 \mathrm{mAb}$ were significants with the next values: $\left(P B_{H D}\right) P<0.001 ;\left(P B_{R A}\right) P<0.01 ;(S M) P<0.01 ;(S F) P<0.01$. The enhanced binding to rsELAM- 1 exhibited by synovial T cells, as compared with $\mathrm{PB}_{\mathbf{R A}}$, reached statistical significance with the next values: $\left(S M / P B_{R A}\right) P<0.01$; and $\left(S F / P B_{R A}\right) P<0.01$. abrogated by both anti- $\alpha 4$ HP2/1 mAb and anti-VCAM-1 4B 9 $\mathrm{mAb}$, but not by the unrelated anti-CD45 D3/9 mAb (Fig. 3).

Regulation of $P B$ and synovial $T$ cell binding to VCAM-I and fibronectin by in vitro activation. VLA-4-mediated adhesion to both FN and VCAM-1 ligands has been reported to be upregulated upon in vitro cell activation (52-54). This enhancement in VLA-4 adhesive properties seems to be due to a qualitative change undergone by this integrin during cellular activation. Previously, we have also documented an enhanced binding to FN by synovial $\mathrm{T}$ cells, as compared with PB T cells in RA patients (37).

We next investigated whether PB and SF T cell attachment to both VLA-4 ligands, VCAM-1, and a $38 \mathrm{kD}$ FN fragment containing the CS-1 domain (FN38) (29), could be further upregulated by in vitro activation. As expected, treatment for 30 min with phorbol esters or crosslinked CD3 mAb enhances PB T cell adhesiveness to both VLA-4 ligands (Fig. 4). By contrast, no significant enhancement in SF $\mathrm{T}$ cell binding to VCAM-1 and FN38 was observed upon PMA and CD3 treatment (Fig. 4). The lack of a further regulation of SF T cell binding to VCAM- 1 and FN38 by in vitro stimulation could be due to their constitutive in vivo-activated state, making them unresponsive to an additional stimulus. Alternatively, one could argue that the ligand concentrations used in this study were high enough to completely saturate their receptors, thus allowing for maximal binding reactions. If this were the case, then one would not detect differences on binding probably reflecting the existence of multiple levels of cellular affinity for FN38 and VCAM-1. To clarify this point, we assayed PMAtreated and untreated synovial and PB T cells for binding to FN38 and rsVCAM-1 applied at different doses. As illustrated in Fig. 5, an increase in cell attachment of PMA-treated versus untreated SF $\mathrm{T}$ lymphocytes was observed at FN38 and rsVCAM- 1 concentrations below $15 \mu \mathrm{g} / \mathrm{ml}$ and $1 \mu \mathrm{g} / \mathrm{ml}$, respectively. Thus, in vivo-activated SF $\mathrm{T}$ cells exhibited a higher capacity than PB T cells to interact with both VLA-4 ligands, but in vitro activation increased the adhesiveness even more, at least partially reflecting qualitative changes of this integrin (37).

Induction of proliferative signals through VLA-4 in T cells from $R A$ patients. The interaction of $\mathrm{T}$ cells with several $\mathrm{ECM}$ proteins such as fibronectin, laminin, or collagen has been reported to trigger mitogenic signals through different VLA 

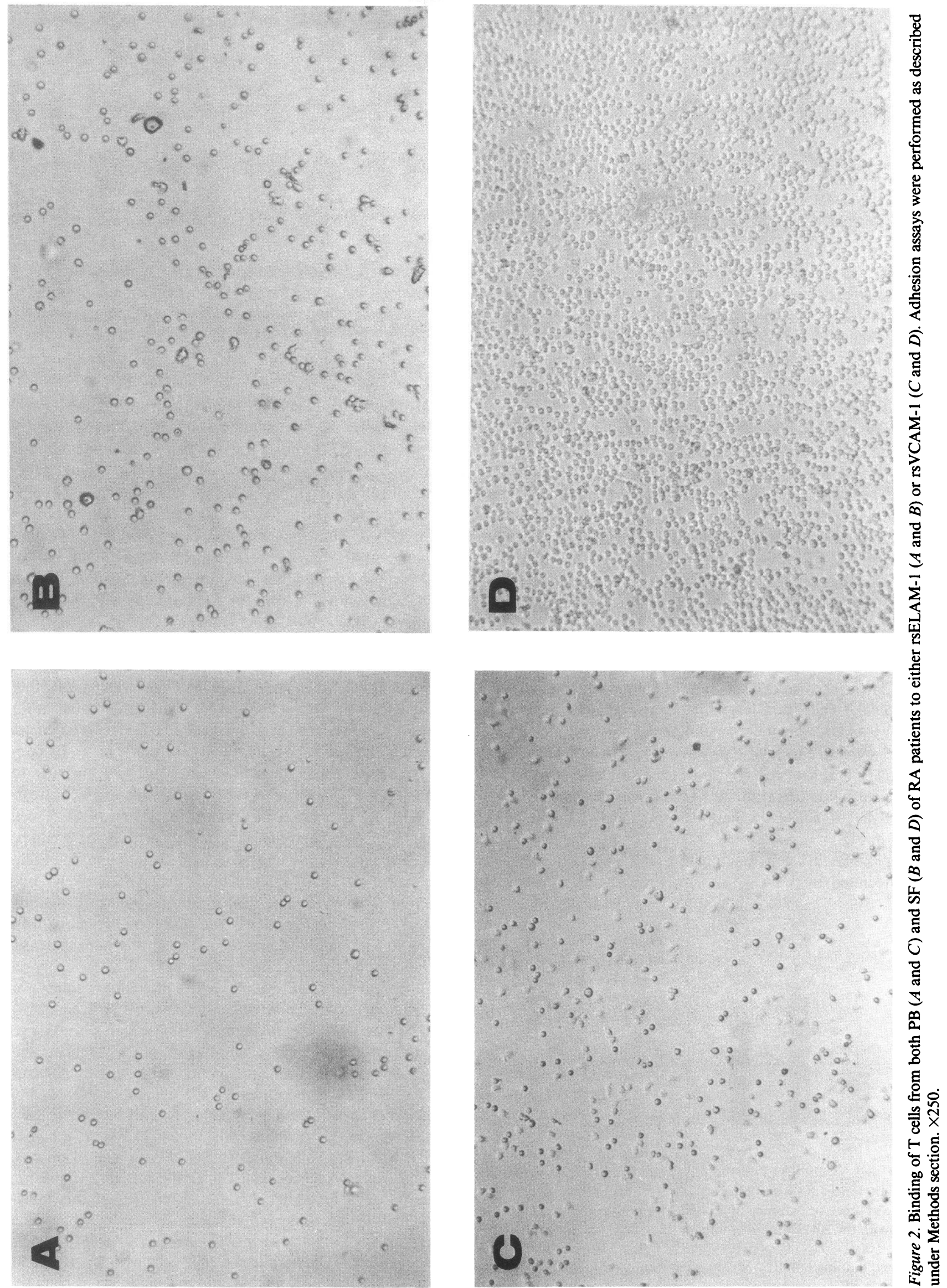


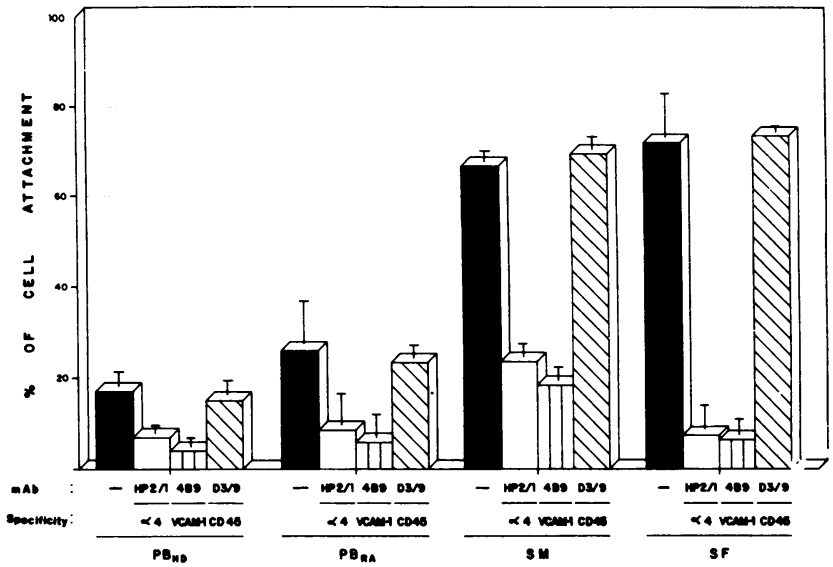

Figure 3. Binding to rsVCAM-1 by $\mathrm{T}$ cells from $\mathrm{PB}$ of healthy donors and from different compartments of RA patients. $\left(P B_{H D}\right) \mathrm{T}$ cells from PB of healthy donors; $\left(P B_{R A}\right)$ T cells from PB of RA patients; $(S M)$ T cells from SM of RA patients; $(S F)$ T cells from SF of RA patients. Adhesion assays were performed as described in Methods, either in the absence of any mAb or in the presence of anti-VLA- $\alpha 4$, antiVCAM-1, or anti-CD45 mAb. The inhibition of $T$ cell binding to rsVCAM- 1 by anti- $\alpha 4 \mathrm{HP} 2 / 1 \mathrm{mAb}$ was significant with the next values: $\left(P B_{H D}\right) P<0.01 ;\left(P B_{R A}\right) P<0.05 ;(S M) P<0.01 ;(S F) P$ $<0.001$. The inhibition of T cell binding to rsVCAM-1 by antiVCAM-1 4B9 mAb reached statistical significance with the next values: $\left(P B_{H D}\right) P<0.01 ;\left(P B_{R A}\right) P<0.05 ;(S M) P<0.01$; $(S F) P$ $<0.001$. The enhancement of synovial T cell binding to rsVCAM-1, as compared with $\mathrm{PB}_{\mathrm{RA}}$, was significant with the next values: (SM) $\left.P B_{R A}\right) P<0.001$ and $\left(S F / P B_{R A}\right) P<0.001$.

members (55-59). Immobilized FN conveys proliferative signals to CD3-activated T cells mainly through VLA-5, but also by VLA-4 (55-58).

To elucidate the response of PB and SF T cells from RA patients to both VLA-4 ligands, proliferative assays with T cells activated with anti-CD3 mAb in conjunction with either FN38 or rsVCAM-1 were carried out. Interestingly, VCAM-1 supported strong comitogenic responses with $\mathrm{CD} 3 \mathrm{mAb}$ in both

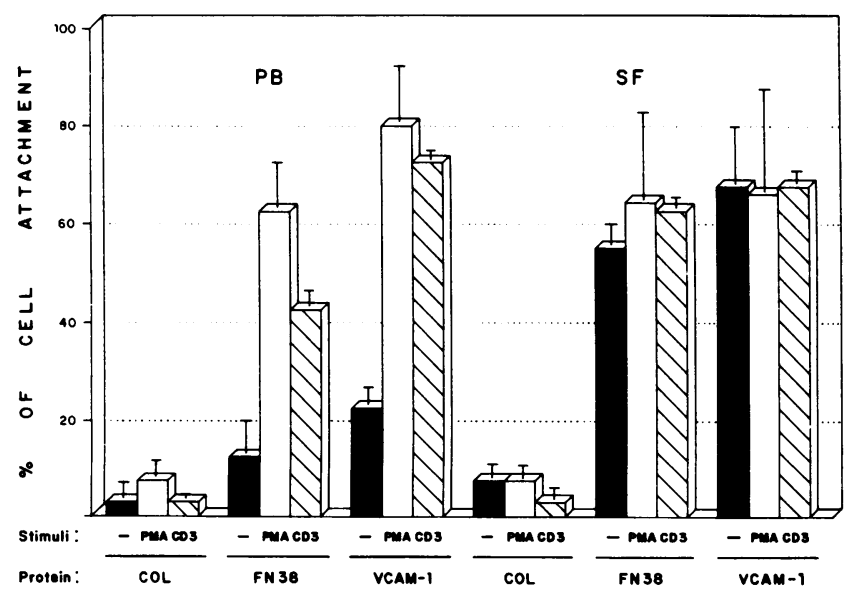

Figure 4. Binding of $\mathrm{T}$ cells from both $\mathrm{PB}$ and SF to either type I collagen (COL), a FN38 fragment, or rsVCAM-1. T cells were either untreated, treated for $30 \mathrm{~min}$ with PMA $50 \mathrm{ng} / \mathrm{ml}$, or treated for 30 min with soluble anti-CD3 SPV-T3b $\mathrm{mAb}(10 \mu \mathrm{g} / \mathrm{ml})$ plus anti-mouse $\mathrm{IgG}$ antiserum $(1 \mu \mathrm{g} / \mathrm{ml})$. Adhesion assays were performed as described in Methods.

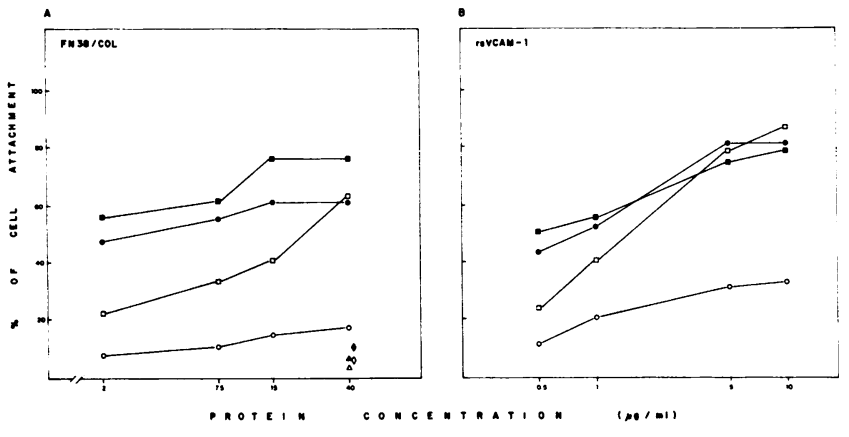

Figure 5. Binding of T cells from PB $(0, \bullet)$ or SF $(\square, \bullet)$ of RA patients to either FN38 $(A)$ or rsVCAM-1 $(B)$ applied to plates at different doses. Binding to type I collagen $(C O L)$ by both PB $(\triangle, \Delta)$ or $\operatorname{SF}(\diamond, \bullet)$ is also represented. T cells were either untreated (open symbols) or treated for $30 \mathrm{~min}$ with PMA $50 \mathrm{ng} / \mathrm{ml}$ (closed symbols).

PB and SF T cells (Table II). FN38 also increased the proliferation of CD3-treated T cells, although in a lower extent than VCAM-1, which is in agreement with previous reports demonstrating that VLA-5 is the major FN receptor implicated in T cell proliferation triggered by this ECM protein (55-58). Neither rsVCAM-1 nor FN38 induced comitogenic effects in combination with PMA, although this phorbol ester showed to be strongly comitogenic with anti-CD69 TP1/8 mAb (data not shown).

\section{Discussion}

The results reported herewith demonstrate that synovial $\mathrm{T}$ cells from RA patients exhibit a higher capacity to interact with VCAM-1, as compared with PB T cells from the same patients. Furthermore, synovial $\mathrm{T}$ cells show an enhanced binding, about twofold, to ELAM-1 which could probably reflect the activity of a $\mathrm{T}$ cell subset. The increased adhesiveness of synovial $T$ cells to their endothelial ligands can thus reflect pathologic phenomena occurring in the inflamed tissue of patients with RA, and, therefore, extend our current understanding of the pathophysiology of this disease. Although the patients stud-

Table II. Comitogenic Effects of FN38 and VCAM-1 in CD3 mAb-stimulated T Cells from PB and SF RA Patients

\begin{tabular}{lccccc}
\hline & \multicolumn{2}{c}{ Experiment 1 } & & \multicolumn{2}{c}{ Experiment 2 } \\
\cline { 2 - 3 } \cline { 5 - 6 } \cline { 5 - 6 } & Medium & CD3 mAb & & Medium & CD3 mAb \\
\hline A. PB & & & & \\
$\quad$ Medium & $0.23 \pm 0.15$ & $17.93 \pm 3.26$ & & $0.34 \pm 0.05$ & $13.42 \pm 1.86$ \\
FN38 & $0.38 \pm 0.23$ & $46.49 \pm 3.75$ & & $0.63 \pm 0.23$ & $21.09 \pm 1.54$ \\
VCAM-1 & $0.24 \pm 0.13$ & $139.17 \pm 7.87$ & & $0.30 \pm 0.05$ & $75.11 \pm 13.97$ \\
B. SF & & & & \\
Medium & $0.42 \pm 0.34$ & $34.84 \pm 1.89$ & & $1.33 \pm 0.66$ & $50.74 \pm 3.45$ \\
FN38 & $0.54 \pm 0.18$ & $71.59 \pm 2.55$ & & $1.39 \pm 0.86$ & $86.53 \pm 7.30$ \\
VCAM-1 & $0.32 \pm 2.33$ & $97.62 \pm 2.07$ & & $2.11 \pm 0.76$ & $164.10 \pm 13.48$
\end{tabular}

Proliferative response of $\mathrm{PB}$ and $\mathrm{SF} T$ cells from RA patients to immobilized CD3 mAb combined with either FN38 or rsVCAM-1. Plates were coated with the different proteins as described under Methods section. Results (in cpm $\times 10^{-3}$ ) represent the medium average of triplicate values plus standard deviation. 
ied were receiving different therapies, the pattern of adhesive reactivity observed was very similar in all of them, which strongly suggests that the observed phenomena were related to disease itself, and not their treatment, age, duration, and evolution of the disease. This fact is also extended to the four patients receiving corticosteroid therapy.

The accumulation of T lymphocytes in the RA SM plays an important role in the development of inflammatory events that leads to articular damage and destruction (1-4). In the early steps of RA, a characteristic feature is the neovascularization of the SM and the formation of perivascular lymphocyte infiltrates (1-4). Additionally, the lining layer, which separates SM from the articular cavity and the SF, undergoes a significant hyperplasia which probably bears relationship to $T$ cell infiltration (1-4). Nevertheless, the mechanisms responsible for the development of these lesions are largely unknown.

The emigration of lymphocytes from PB to SM requires their prior binding to EC. It is known that a number of ligands (ICAM-1, VCAM-1, ELAM-1, CD62/GMP140/PADGEM, etc.) are induced on EC surface in response to inflammatory agents (reviewed in references 5 and 6). Recent reports indicate that initial interactions of neutrophils with $\mathrm{EC}$ involve the CD62- and ELAM-1-mediated rolling of cells on the vessel wall $(12,14)$. The integrins seem to participate in the next step of cell traffic, which is a reinforced adhesion, the cellular extravasation and migration into inflamed tissue which occur subsequent to leukocyte-EC selectin-mediated contacts $(12,14)$. All these sequential processes have been reported for neutrophils, although the interaction of $\mathrm{T}$ cells with either in vitro-activated or chronically inflamed EC in skin using an ELAM-1-mediated mechanism has also been reported $(21-23,49)$.

Our results show that synovial $T$ cells display a higher adhesiveness to ELAM-1, as compared with PB T cells. Most of such synovial $\mathrm{T}$ cells express a memory CD45RO+ phenotype $(33,35,37)$, a feature that has been correlated with the $T$ cell binding to ELAM-1 (22). The level of ELAM-1 expression by EC from inflamed synovium is reported to be similar to that found in other chronic inflammatory processes, although lower than that reported from chronic skin lesions (49). In that latter setting, a specific $T$ cell subset displaying ELAM-1 binding ability has been described to bear the CLA-HECA 452 antigen (49). Whether this synovial $T$ cell subpopulation binding ELAM-1 could also express that marker, or other synoviumrestricted antigens, requires further studies. It is noteworthy that the HECA 452 antigen has been detected on dendritic cells and EC of SM from RA (60).

In a second step of cellular migration, leukocyte interaction with EC involves the integrin family members. These adhesion molecules would allow for a reinforced cell attachment and then the transendothelial migration $(11,12,14)$. According to current knowledge, integrin-mediated $\mathrm{T}$ cell binding to activated endothelium involves mostly LFA-1/ICAM-1 and VLA4/VCAM-1 interactions (7). The expression of ICAM-1 in RA synovial tissues is known to be characteristic not only for EC but also macrophages, lining layer cells, and some lymphocytes $(50,61)$. Studies on the role of LFA-1/ICAM-1 interactions in synovial lesions of RA patients are currently underway in this laboratory. Interestingly, ICAM-1 has been found to play a role in the pathogenesis of other chronic autoimmune disease such as murine lupus nephritis (62).

Our results clearly demonstrate an increased VLA-4-mediated binding to VCAM-1 by most synovial T cells. This en- hanced adhesion to VCAM- 1 could be related to their activated (AIM/CD69+, DR + ) and memory (CD45RO+) phenotype (32-37), since it has been recently reported that this interaction is enhanced upon in vitro activation of $\mathrm{T}$ cells, particularly those possessing a memory phenotype (52).

Finally, our data suggest the existence of several levels of cellular affinity for VLA-4 ligands. Thus, the enhanced binding of synovial T cells to both VCAM-1 and FN38 reflects an in vivo upregulated state of affinity. However, a further increase in SF T cell binding to both VLA-4 ligands could be achieved using additional in vitro stimuli like phorbol esters, or the engagement of the CD3-TcR complex. Thus, those stimuli can further enhance the ligand binding of cells that have already developed binding activities in vivo (37). In addition, to bind VCAM-1, VLA-4 mediates homotypic cell contacts in a VCAM-1-independent manner $(63,64)$. Whether this adhesive property of VLA-4 is also upregulated in synovial T cells is currently under investigation.

Both ELAM-1 and VCAM-1 might participate in subsequent steps of T cell adhesion to EC and migration into the SM of RA. Very recently, it has been described that neutrophil interaction with ELAM-1 activates Mac-1, thus enhancing the avidity of this integrin to bind its ligands (14). It is known that memory and naive $T$ cells exhibit different recirculation pathways, with memory CD45RO+ T cells leaving the bloodstream through the peripheral tissue endothelium (65). It could be hypothesized that a subset of CD45RO+ PB T cells in RA patients interacts with ELAM-1 on activated EC in inflamed tissue. This interaction could then increase VLA-4 (and possibly LFA-1) avidity for VCAM-1 (possibly for ICAM-1), allowing T cells to enter into inflamed synovium. The adhesion and transmigration of lymphocytes through EC is known to be regulated by cytokines, inflammatory mediators, and chemotactic agents $(5,6,66,67)$. It was recently suggested that ELAM-1 could play a chemoattractant role directing the movement of leukocytes (14). The pathological significance of an enhanced binding of SM and SF T cells to ELAM-1, that is restricted in RA synovial tissue to the EC, after their entry into SM, remains to be determined.

VLA-4 also participates in T cell binding to FN, and this interaction is enhanced upon in vitro cellular activation $(29$, $30,53,54)$. Accordingly, we have previously documented an increased binding of synovial $T$ cells to $F N$ in RA patients (37). SM and SF from RA have been reported to contain high concentrations of FN (68). Therefore, $\mathrm{T}$ lymphocyte interaction with FN in the SM could constitute an important feature in the infiltration and maintenance of cells perpetuating the tissue injury in this compartment $(37,69)$, and can convey proliferative signals to infiltrating $T$ lymphocytes (see above and 5558). The high expression of VCAM-1 by the RA lining layer could also be involved in the migration of infiltrating cells to the lining, thus participating in its hyperplasia and in the resulting increased cellularity of SF. We have found that the interaction between VLA-4 and VCAM-1 also delivers proliferative signals to synovial $\mathrm{T}$ cells. This signaling pathway, probably acting together with that of LFA-1/ICAM-1 reported in normal $T$ cells (70), could represent important mechanisms in synovial $\mathrm{T}$ cell proliferation. The interaction of $\mathrm{T}$ lymphocytes with the synovial antigen-presenting macrophages, expressing high levels of VCAM-1 (51), is thought to participate in the initiation of the immune response in the RA synovitis $(2,71)$.

The pathogenesis of tissue injury in RA remains obscure. 
We believe that the results presented here shed new light on the immune mechanisms responsible for tissue infiltration in this disease, highlighting the possible role of adhesion molecules in directing $T$ cell traffic to synovial tissue, and enhancing their in situ localization, activation, and proliferation.

\section{Acknowledgments}

We greatly appreciate the helpful discussion and critical reading of this manuscript by Drs. A. Gorski and A. L. Corbí. We also thank Drs. Harlan, Hardy, and De Vries for their kind supply of mAb, and Dr. García-Pardo for the generous gift of the fibronectin fragment FN38.

This work was supported by grants from Insalud Fis 90/0096 and 91/0259, and from Fundación Ramón Areces.

\section{References}

1. Cavender, P., D. Haskard, C. L. Yu, P. Miossec, M. Oppenheimer-Marks, and M. Ziff. 1987. Pathways to chronic inflammation in Rheumatoid synovitis. Fed. Proc. 46:113-117.

2. Ziff, M. 1989. Role of endothelium in chronic inflammation. Springer Semin. Immunopathol. 11:199-214.

3. Jalkanen, S. 1989. Leukocyte-endothelial cell interaction and the control of leukocyte migration into inflammed synovium. Springer Semin. Immunopathol. $11: 187-198$.

4. Harris, E. D., Jr. 1990. Rheumatoid arthritis. Pathophysiology and implications for therapy. N. Engl. J. Med. 322:1277-1288.

5. Stoolman, L. M. 1989. Adhesion molecules controlling lymphocyte migration. Cell. 56:907-910.

6. Osborn, L. 1990. Leukocyte adhesion in inflammation. Cell. 62:3-5.

7. Springer, T. A. 1990 . Adhesion receptors in the immune system. Nature (Lond.). 346:425.

8. Ruoslahti, E. 1991. Integrins. J. Clin. Invest. 87:1-5.

9. Bevilacqua, M. P., S. Stengelin, M. A. Gimbrone, Jr., and B. Seed. 1989. Endothelial leukocyte adhesion molecule 1: an inducible receptor for neutrophils related to complement regulatory proteins and lectins. Science (Wash. DC). 243:1160-1164.

10. Larsen, E., R. Celi, G. E. Gilber, B. C. Furie, J. K. Erban, R. Bonfanti, D. D. Wagner, and B. Furie. 1989. PADGEM protein: a receptor that mediates the interaction of activated platelets with neutrophils and monocytes. Cell. 59:305-312.

11. Arfors, K. E., C. Lundberg, L. Lindbom, K. Lundberg, P. G. Beatty, and J. M. Harlan. 1987. A monoclonal antibody to the membrane glycoprotein complex CD 18 inhibits polymorphonuclear leukocyte accumulation and plasma leakage in vivo. Blood. 69:338-340.

12. Lawrence, M. B., and T. A. Springer. 1991. Leukocytes roll on a selectin at physiologic flow rates: distinction from and prerequesite for adhesion through integrins. Cell. 65:859-873.

13. Luscinskas, F. W., M. I. Cybolsky, J. M. Kiely, C. S. Peckins, V. M. Davis, and M. A. Gimbrone, Jr., 1991. Cytokine-activated human endothelial monolayers support enhanced neutrophil transmigration via a mechanism involving both endothelial-leukocyte adhesion molecule-1 and intercellular adhesion molecule-1. J. Immunol. 146:1617-1625.

14. Lo, S. K., S. Lee, R. A. Ramos, R. Lobb, M. Rosa, G. Chi-Rosso, and S. D. Wright. 1991. Endothelial-leukocyte adhesion molecule 1 stimulates the adhesive activity of leukocyte integrin CR3 (CD1lb/CD18, Mac-1, $\alpha \mathrm{m} \beta 2)$ on human neutrophils. J. Exp. Med. 173:1493-1500.

15. Tedder, T. F., C. M. Isaacs, T. J. Ernst, G. D. Demetri, D. A. Adler, and C. M. Disteche. 1989. Isolation and chromosomal localization of cDNAs encoding a novel human lymphocyte homing receptor cell surface molecule, LAM-1: homology with the mouse lymphocyte homing receptor and other human adhesion proteins. J. Exp. Med. 170:123-133.

16. Springer, T. A., and L. A. Lasky. 1991. Sticky sugars for selectins. Nature (Lond.). 349:196-197.

17. Brandley, B. K., Swiedler, S. J., and P. W. Robbins. 1990. Carbohydrate ligands of the LEC cell adhesion molecules. Cell. 63:861-863.

18. Lowe, J. B., L. M. Stoolman, R. P. Nair, R. D. Larsen, T. L. Berhend, and R. M. Marks. 1990. ELAM-1-dependent cell adhesion to vascular endothelium determined by a transfected human fucosyltransferase cDNA. Cell. 63:475-484

19. Goelz, S. E., C. Hession, D. Goff, B. Griffiths, R. Tizard, B. Newman, G. Chi-Rosso, and R. Lobb. 1990. ELFT: A gene that directs the expression of an ELAM-1 ligand. Cell. 63:1349-1356.

20. Larsen, E., T. Palabrica, S. Sajer, G. E. Gilbert, D. D. Wagner, B. C. Furie, and B. Furie. 1990. PADGEM-dependent adhesion of platelets to monocytes and neutrophils is mediated by a lineage specific carbohydrate, LNFIII (CD15). Cell. 63:467-474.
21. Graber, N., T. V. Gopal, D. Wilson, L. D. Beall, T. Polte, and W. Newman. 1990. T cells bind to cytokine-activated endothelial cells via a novel inducible sialoglycoprotein and ELAM-1. J. Immunol. 145:819-830.

22. Shimizu, Y., S. Shaw, N. Graber, T. V. Gopal, K. J. Horgan, G. A. van Seventer, and W. Newman. 1991. Activation-independent binding of human memory T cells to adhesion molecule ELAM-1. Nature (Lond.). 349:799-802.

23. Lobb, R. R., G. Chi-Rosso, D. R. Leone, M. D. Rosa, S. Bixler, B. M. Newman, S. Luhowskyj, C. D. Benjamin, I. G. Dougas, S. E. Goelz, et al. 1991. Expression and functional characterization of a soluble form of endothelial-leukocyte adhesion molecule-1 (ELAM-1). J. Immunol. 147:124-129.

24. Marlin, S. D., and T. A. Springer. 1987. Purified intracellular adhesion molecule-1 is a ligand for lymphocyte function associated-antigen 1 (LFA-1). Cell. 51:813-819.

25. Staunton, D. E., M. L. Dustin, and T. A. Springer. 1989. Functional cloning of ICAM-2, a cell adhesion ligand for LFA-1 homologous to ICAM-1. Nature (Lond.). 339:61-64.

26. de Fougerolles, A. R., S. A. Stacker, R. Schwarting, and T. A. Springer. 1991. Characterization of ICAM-2 and evidence for a third counter-receptor for LFA-1. J. Exp. Med. 174:253-269.

27. Elices, M. J., L. Osborn, Y. Takada, C. Crouse, S. Luhowskyj, M. E. Hemler, and R. R. Lobb. 1990. VCAM-1 on activated endothelium interacts with the leukocyte integrin VLA-4 at a site distinct from VLA-4/fibronectin binding site. Cell. 60:577-584.

28. Rice, G., J. Munro, and M. Bevilacqua. 1990. Inducible cell adhesion molecule 110 (INCAM-110) is an endothelial receptor for lymphocytes: A CD11/ CD18-independent adhesion mechanism. J. Exp. Med. 171:1369-1374.

29. Wayner, E. A., A. García-Pardo, M. J. Humphries, J. A. MacDonald, and W. G. Carter. 1989. Identification and characterization of the T lymphocyte adhesion receptor for an alternative cell attachment domain (CS-1) in plasma fibronectin. J. Cell Biol. 109:1321-1330.

30. García-Pardo, E. A. Wayner, W. G. Carter, and O. C. Ferreira. 1990. Human B lymphocytes define an alternative mechanism of adhesion to fibronectin. The interaction of $\alpha 4 \beta 1$ integrin with the LHGPEILDVPST sequence of the type III connecting segment is sufficient to promote cell adhesion. J. Immunol. 144:3361-3366.

31. Yu, D. T. Y., R. J. Winchester, S. M. Ru, A. Gibofsky, H. S. Ko, and H. J. Kunkel. 1980. Peripheral blood Ia positive cells. Increases in certain diseases and after immunization. J. Exp. Med. 151:91-101.

32. Hemler, M. E., D. Glass, J. S. Coblyn, and J. G. Jacobson. 1986. Very late activation antigens on rheumatoid synovial fluid $T$ lymphocytes: association with stages of T cell activation. J. Clin. Invest. 78:696-702.

33. Pitzalis, C., G. Kingsley, J. Murphy, and G. Panayi. 1987. Abnormal distribution of helper-inducer and suppressor inducer $T$ lymphocyte subsets in the rheumatoid joint. Clin. Immunol. Immunopathol. 45:252-258.

34. Cush, J. J., and P. E. Lipsky. 1988. Phenotypic analysis of synovial tissue and peripheral blood lymphocytes isolated from patients with rheumatoid arthritis. Arthritis Rheum. 32:386-392.

35. Pitzalis, C. G. Kingsley, D. Haskard, and G. Panayi. 1988. The preferential accumulation of helper-inducer $T$ lymphocytes in inflammatory lesions: evidence for regulation by selective endothelial and homotypic adhesion. Eur. $J$. Immunol. 18:1397-1404.

36. Laffón, A., F. Sánchez-Madrid, M. O. de Landázuri, A. Ariza, C. Ossorio, and $P$. Sabando. 1989. Very late activation antigen on synovial fluid $T$ cells from patients with rheumatoid arthritis and other rheumatic diseases. Arthritis. Rheum. 32:386-392.

37. Laffón, A., R. García-Vicuña, A. Humbría, A. A. Postigo, A. L. Corbí, M. O. de Landázuri, and F. Sánchez-Madrid. 1991. Upregulated expresion and function of VLA-4 fibronectin receptor on human activated T cells in rheumatoid arthritis. J. Clin. Invest. 88:546-552.

38. Arnett, F. C., S. M. Edworthy, D. A. Bloch, D. J. McShane, J. F. Fries, N. S. Cooper, L. A. Healey, S. R. Kaplan, M. H. Liang, H. S. Luthra, et al. 1988. The American Rheumatism Association 1987 revised criteria for the classification of rheumatoid arthritis. Arthritis Rheum. 31:315-324.

39. Spits, H., H. Yssel, J. Leeuwenberg, and J. E. de Vries. 1985. Antigen-specific cytotoxic $T$ cell and antigen-specific proliferating $T$ cell clones can be induced to cytolitic activity by monoclonal antibodies against T3. Eur. J. Immunol. 15:88-95.

40. Sánchez-Madrid, F., M. O. de Landázuri, G. Morago, M. Cebrián, A. Acevedo, and C. Bernabeu. 1986. VLA-3: a novel polypeptide association within the VLA molecular complex: cell distribution and biochemical characterization. Eur. J. Immunol. 16:1343-1349.

41. Hemler, M. E., F. Sánchez-Madrid, T. J. Flotte, A. M. Krensky, S. J. Burakoff, A. K. Bhan, T. A. Springer, and J. L. Strominger. 1984. Glycoproteins of 210,000 and 130,000 m.w. on activated T cells: cell distribution and antigenic relation to components on resting cells and T cell lines. J. Immunol. 132:30113018.

42. Carlos, T., R. Swartz, N. L. Kovach, E. Yee, M. Rosso, L. Osborn, G. Chi-Rosso, B. Newman, R. Lobb, and J. Harlan. 1990. Vascular cell adhesion molecule-1 (VCAM-1) mediates lymphocyte adhesion to cytokine-activated cultured human endothelial cells. Blood. 76:965-970. 
43. Benjamin, C., I. Dougas, G. Chi-Rosso, S. Luhowskyj, M. Rosa, B. Newman, L. Osborn, G. Vassallo, C. Hession, S. Goelz, et al. 1990. A blocking monoclonal antibody to endothelial adhesion molecule 1 (ELAM-1). Biochem. Biophys. Res. Commun. 171:348-353.

44. Cebrián, M., E. Yague, M. Rincón, M. López-Botet, M. O. de Landázuri, and F. Sánchez-Madrid. Triggering of T cell proliferation through AIM, an activation inducer molecule on activated human lymphocytes. J. Exp. Med. 168:1621-1637.

45. Pulido, R., M. Cebrián, A. Acevedo, M. O. de Landázuri, and F. SánchezMadrid, 1988. Comparative biochemical and tissue distribution of four CD45 antigen specificities. J. Immunol. 140:3851-3857.

46. Smith, S. H., M. H. Brown, D. Rowe, R. E. Callard, and P. C. L. Beverley 1986. Functional subsets of human helper-inducer cells defined by a new monoclonal antibody, UCHL1. Immunology. 58:63-70.

47. Fukushima, K., M. Hirota, P. I. Terasaki, A. Wakisaka, H. Togashi, D. Chia, N. Suyama, Y. Fukushi, E. Nudelman, and S. I. Hakomori. 1984. Characterization of sialosylated Lewis ${ }^{x}$ as a new tumor-associated antigen. Cancer Res. 44:5279-5285.

48. Lobb, R., G. Chi-Rosso, D. Leone, M. Rosa, B. Newman, S. Luhowskyj, L. Osborn, S. Schiffer, C. Benjamin, J. Dougas, et al. 1991. Expression and functional characterization of a soluble form of vascular cell adhesion molecule 1 . Biochem. Biophys. Res. Commun. 178:1498-1504.

49. Picker, L. J., T. K. Kishimoto, C. W. Smith, R. A. Warnock, and E. C Butcher. 1991. ELAM-1 is an adhesion molecule for skin-homing T cells. Nature (Lond.). 349:796-799.

50. Koch, A. E., J. C. Burrows, G. K. Haynes, T. M. Carlos, J. M. Harlan, and S. J. Leibovich. 1991. Immunolocalization of endothelial and leukocyte adhesion molecules in human rheumatoid and osteoarthritic synovial tissues. Lab. Invest. 64:313-320.

51. Rice, G. E., J. M. Munro, C. Corless, and M. P. Bevilacqua, 1991. Vascular and nonvascular expression of INCAM-110. Am. J. Pathol. 138:385-593.

52. Shimizu, Y., W. Newman, T. V. Gopal, K. J. Horgan, N. Graber, L. D. Beall, G. A. van Seventer, and S. Shaw. 1991. Four molecular pathways of T cell adhesion to endothelial cells: roles of LFA-1, VCAM-1, and ELAM-1 and changes in pathway hierarchy under different activation conditions. J. Cell Biol. 113:1203-1212.

53. Shimizu, Y., G. A. van Seventer, K. J. Horgan, and S. Shaw. 1990. Regulated expression and function of three VLA $(\beta 1)$ integrin receptors on T cells. Nature (Lond.). 345:250-253

54. Postigo, A. A., R. Pulido, M. R. Campanero, A. Acevedo, A. GarcíaPardo, A. L. Corbí, F. Sánchez-Madrid, and M. O. de Landázuri. 1991. Differential expression of VLA-4 integrin by resident and peripheral blood B lymphocytes. Acquisition of functionally active $\alpha 4 \beta 1$ fibronectin receptors upon B cell activation. Eur. J. Immunol. 21:2437-2445.

55. Matsuyama, T., A. Yamada, J. Kay, K. M. Yamada, S. K. Akiyama, S. F. Schlossman, and C. Morimoto. 1989. Activation of CD4 cells by fibronectin and anti-CD3 antibody. A synergistic effect mediated by the VLA- 5 fibronectin receptor complex. J. Exp. Med. 170:1133-1148.

56. Nojima, Y., M. J. Humphries, A. P. Mould, A. Komoriya, K. M. Yamada, S. F. Schlossman, and C. Morimoto. 1990. VLA-4 mediates CD3 dependent
CD4 + T cell activation via the CS1 alternatively spliced domain of fibronectin. $J$ Exp. Med. 172:1185-1192.

57. Shimizu, Y., G. A. van Seventer, K. J. Horgan, and S. Shaw. 1990. Costimulation of proliferative responses of resting CD4+ T cells by interaction of VLA-4 and VLA-5 with fibronectin or VLA-6 with laminin. J. Immunol. 145:59-67.

58. Davis, L. S., N. Oppenheimer-Marks, J. L. Bednarczyk, B. W. McIntyre, and P. E. Lipsky. 1990. Fibronectin promotes proliferation of naive and memory T cells by signaling through both the VLA-4 and VLA- 5 integrin molecules. $J$. Immunol. 125:785-793.

59. Dang, N. H., Y. Torimoto, S. F. Schlossman, and C. Morimoto. 1990. Human CD4 helper T cell activation functional involvement of two distinct collagen receptors, 1FT and VLA integrin family. J. Exp. Med. 172:649-652.

60. van Dinther-Janssen, A. C. H. M., S. T. Pals, R. Scheper, F. Bredveld, and C. J. L. M. Meijer. 1990. Dendritic cells and high endothelial venules in the rheumatoid synovial membrane. J. Rheumatol. 17:11-17.

61. Hale, L. P., M. E. Martin, D. E. McCollum, J. A. Nunley, T. A. Springer, K. H. Singer, and B. F. Haynes. 1989. Immunohistologic analysis of the distribution of cell adhesion molecules within the inflammatory synovial microenvironment. Arthritis Rheum. 32:22-30.

62. Withrich, R. P., A. M. Jevnikar, F. Takei, L. H. Glimcher, and V. E. Kells. 1990. Intercellular adhesion molecule-1 (ICAM-1) expression is regulated in autoimmune murine lupus nephritis. Am. J. Pathol. 136:441-450.

63. Campanero, M. R., R. Pulido, A. Ursa, M. Rodriguez-Moya, M. O. de Landázuri, and F. Sánchez-Madrid. 1990. An alternative leukocyte homotypic adhesion mechanism, LFA-1/ICAM-1-independent, triggered through the human VLA-4 integrin. J. Cell Biol. 210:2157-2163.

64. Bednarczyk, J. L., and T. W. McIntyre. 1990. A monoclonal antibody to VLA-4 $\alpha$ chain (CDw 49d) induces homotypic lymphocyte aggregation. J. Immunol. 144:777-784.

65. Mackay, C. R., W. L. Marston, and L. Dudler. 1990. Naive and memory T cells show distinct pathways of lymphocyte recirculation. J. Exp. Med. 171:801807.

66. Oppenheimer-Marks, N., and M. Ziff. 1988. Migration of lymphocytes through endothelial cell monolayers: augmentation by interferon-gamma. Cell. Immunol. 114:307-323.

67. Turunen, J. P., P. Mattila, and R. Renkonen. 1990. cAMP mediates IL-1 lymphocyte penetration through endothelial monolayers. J. Immunol. 145:4192-4197.

68. Carsons, S., M. W. Mosesson, and H. S. Diamond. 1981. Detection and quantification of fibronectin in synovial fluid from patients with rheumatic diseases. Arthritis Rheum. 124:1261-1267.

69. Herbert, K. W., J. S. Coppock, A. M. Griffith, A. Willians, M. W. Robinson, and D. L. Scott. 1987. Fibronectin and immune complexes in rheumatoid diseases. Ann. Rheum. Dis. 46:734-740.

70. van Seventer, G. A., Y. Shimizu, K. J. Horgan, and S. Shaw. 1990. The LFA-1 ligand ICAM-1 provides an important costimulatory signal for $\mathrm{T}$ cell receptor-mediated activation of resting T cells. J. Immunol. 144:4579-4586.

71. Janossy, G., O. Duke, L. W. Poulter, G. Panayi, M. Bofill, and G. Goldstein. 1981. Rheumatoid Arthritis: a disease of T lymphocyte/macrophage immunoregulation. Lancet. 17:839-842. 